\title{
Effect of participation in physical education and conditioning programme on flexibility
}

\section{HILAL AHMAD DAR, HARTEJ SINGH ${ }^{1}$ AND NADEEM AHMAD DAR ${ }^{2}$}

Received : 21.07.2014; Accepted : 26.03.2015

Members of the Research Forum

Associated Authors:

${ }^{1}$ Govt. College of Physical

Education, Ganderbal, KASHMIR (J \& K) INDIA

${ }^{2}$ Directorate of Physical Education and Sports, University of Kashmir, KASHMIR (J \& K) INDIA

Author for correspondence: HILAL AHMAD DAR Govt. College of Physical Education, Ganderbal, KASHMIR (J\&K) INDIA

Email: drhilal4@gmail.com

\section{-ABSTRACT}

The purpose of the present study was to determine the effect of participation in physical education and conditioning programme on flexibility. To obtain data for the present study, thirty $(\mathrm{N}=30)$ male subjects has been selected from Govt. College of Physical Education, Ganderbal, Kashmir, $\mathrm{J} \& \mathrm{~K}$, India. The subjects were enrolled in B.P.Ed (one year course). Random sampling technique was used to select the subjects. All the subjects were resided in the hostel of college. The age of the subjects ranged between 21-25 years. Shoulder flexibility test, sit and reach test and spine flexibility test were used to collect the data. Pre-test and post test were conducted. "T" test was applied to determine the significant difference among the subjects. The level of significance was set at 0.05 . The results were found statistically significant between pre-test and post test of the subjects.

- KEY WORDS : Shoulder flexibility, Spine flexibility, Sit and reach, Fitness, Conditioning

- HOW TO CITE THIS PAPER : Dar, Hilal Ahmad, Singh, Hartej and Dar, Nadeem Ahmad (2015). Effect of participation in physical education and conditioning programme on flexibility. Internat. J. Phy. Edu., 8 (1): 65-66. 